\title{
Short-term health impact assessment after Irma in French islands
}

\author{
Elise DAUDENS-VAYSSE ${ }^{1}$, Marie BARRAU ${ }^{1}$, Lydéric AUBERT ${ }^{1}$, Patrick PORTECOP ${ }^{2}$, Eric \\ FONTANILLE ${ }^{3}$, Cécile Forgeot ${ }^{1}$, Pierre-Marie LINET ${ }^{4}$, Lazare NOUBOU ${ }^{5}$, Didier ROUX 6 , Céline \\ GENTIL ${ }^{1}$, Philippe MALFAIT ${ }^{1}$, Manuel ZURBARAN ${ }^{1}$, Quiterie MANO ${ }^{1}$, Frédérique DORLEANS ${ }^{1}$, \\ Isabelle PONTAIS ${ }^{1}$, Harris GLADONE${ }^{7}$, Anthony FORBIN 7 , Tiphanie SUCCO ${ }^{1}$, Céline Caserio- \\ Schönemann ${ }^{1}$, Caroline SIX ${ }^{1}$
}

${ }^{1}$ Santé publique France, Fort-de-France, Martinique, ${ }^{2}$ SAMU 971, Pointe-à-Pitre, Guadeloupe, ${ }^{3}$ Agence régionale de santé de Martinique, Fort-deFrance, Martinique, ${ }^{4}$ Centre hospitalier Fleming, Marigot, Saint Martin (French part), ${ }^{5}$ Centre Hospitalier de Bruyn, Gustavia, Saint Barthélemy, ${ }^{6}$ Agence régional de santé de Guadeloupe, Saint-Martin et Saint-Barthélemy, Pointe-à-Pitre, Guadeloupe, ${ }^{7}$ GCS e-Santé ARCHIPEL 97-1, BaieMahault, Guadeloupe

\section{Objective}

Describe short-term health effects of the Hurricane using the syndromic surveillance system based on emergency departments, general practitioners and dispensaries in Saint-Martin and Saint-Barthélemy islands from September 11, 2017 to October $29,2017$.

\section{Introduction}

In Saint-Martin (31 949 inhabitants) and Saint-Barthélemy (9 625 inhabitants) islands in the French West Indies, the surveillance system is based on several data sources: (1) a syndromic surveillance system based on two emergency departments (ED) of SaintBarthélemy (HL de Bruyn) and Saint-Martin (CH Fleming) and on mortality (SurSaUD® network [1])); (2) a network of sentinel general practitioners (GP's) based on the voluntary participation of 10 GPs in Saint- Martin and 5 in Saint-Barthélemy; (3) the notifiable diseases surveillance system (31 notifiable diseases to individual case-specific form); (4) the regional surveillance systems of leptospirosis and arboviruses based on the biological cases reported by physicians and laboratories of two islands. On September 6, 2017, Hurricane Irma struck Saint-Martin and Saint-Barthélemy islands. Both islands were massively destroyed. This storm led to major material damages, such as power outages, disturbance of drinking water systems, road closures, destruction of medical structures and evacuation or relocation of residents. In this context, the usual monitoring system did not work and life conditions were difficult. The regional unit of French National Public Health Agency set up an epidemiological surveillance by sending epidemiologists in the field in order to collect data directly from ED physicians, GP's and in dispensaries. Those data allowed to describe short-term health effects and to detect potential disease outbreaks in the aftermath of Hurricane Irma. This paper presents results of the specific syndromic surveillance.

\section{Methods}

Before Irma, ED data were collected daily directly from patients' computerized medical files that were filled in during medical consultations at ED. Among the collected variables, the diagnosis was categorized according to the $10^{\text {th }}$ revision of the International Classification of Diseases (ICD-10). This surveillance system was completed by aggregated data of Emergency Medical Services (EMS), also including medical diagnosis coded using the ICD10.

Because of the sudden disruption in hospital departments due to hurricane, electronic transmission was stopped. To replace it, ED data collection turned temporary into paper-forms and several epidemiologists were sent in Saint-Martin and Saint-Barthélemy to collect data directly from the ED physicians. This system remained until the end of October when connections and data transmi ssion were restored. Because of destruction of medical structures, dispensaries were opened in different strategic areas of the island, 3 in Saint-Martin and none in Saint-Barthélemy. General practitioners have progressively reopened their practice (8 GP's in SaintMartin and 5 in Saint-Barthélemy) and patient's data were collected and integrated into the surveillance system. 
Based on a literature review and former experience, the main pathologies identified for the health risk assessment were: (1) somatic pathologies directly or indirectly related to the hurricane (trauma, wounds, cuts, burns, secondary infection); (2) infectious diseases related to the lack of hygiene partly due to damaged water and electricity networks and unavailable health care structures (gastroenteritis, food infections, respiratory diseases, skin infections, tetanus and other pathologies that may occur in the longer term linked to the incubation period especially leptospirosis and hepatitis A); (3) chronic pathologies by discontinuity of care (renal insufficiency, diabetic, cardio-respiratory decompensation, etc.); (4) pathologies related to animal bites and mosquito bites (vectorborne diseases); (5) psychological and / or psychiatry disorders.

Then in the French West Indies, from September 11 to October 29,2017, data were routinely analyzed to detect and follow-up various expected or unusual variations of one or more pathology of the above list.

\section{Results}

The following week after Irma (2017-37), the weekly number of ED visits compared to the mean activity observed in normal situation has increased: 1225 ED visits vs. 313 in 2017-35 in Saint-Martin and 227 ED visits vs. 94 ED visits in 2017-35 in SaintBarthélemy. ED activity has gradually decreased to finally return to a based-activity as observed before the hurricane at the end of October. From September 11 to October 29, 25\% of recorded emergency consultations in Saint-Martin island were trauma, wounds, burns and cuts. As in Saint-Martin, $42 \%$ of emergency visits in Saint-Barthélemy were pathologies directly or indirectly related to the passage of Irma (trauma, wounds, etc). Others major causes of ED visits were for treatment renewal (diabetes, renal insufficiency, etc.) and gyneco-obstetric activity because general practitioners had stopped their activity. In dispensaries and general practitioners, the most common pathology was gastroenteritis (11\% in Saint-Martin) over the entire period of surveillance. At the beginning of the surveillance, skin infections were the most frequently found (20\%) in Saint-Martin and psychological disorders (3\%) in Saint-Bartélemy, while at the end respiratory infections were the most frequent (6\%) in both islands. No increase in visits for chronic diseases, food-borne diseases, acute respiratory or diarrhea illness were detected. No autochthonous confirmed cases of cholera, leptospirosis, vector-bone disease, hepatitis A or typhoid fever had been reported, due to the destruction of the laboratory.

\section{Conclusions}

Syndromic surveillance in the French West Indies allowed the epidemiologists to assess rapidly the health impact of hurricane in Saint-Martin and Saint-Barthélemy.

The well-established relations between French National Public Health Agency and local professionals of both affected islands allowed to temporary switch from an electronic into a paper-based data transmission without any interruption of data analysis.

Although several cluster suspicions have been investigated (especially of gastroenteritis, scabies, etc), no massive outbreak was detected. Then even with a degraded system, syndromic surveillance allowed to reinsure authority of the absence of major health impact due to Irma.

\section{Acknowledgement}

The authors thank the epidemiology team: Christine CASTOR, François CLINARD, Pauline DELEZIRE, Erica FOUGERE, Jean-Rodrigue NDONG, Valérie PONTIES, Hélène PROUVOST, Cyril ROUSSEAU and Aymeric UNG.

The authors thank the emergency departments CH Fleming and HL De Bruyn and general practitioners for providing data and their contribution to the surveillance. The authors thank the French Health Regional Agency (ARS) of Martinique and Guadeloupe, Saint-Martin and Saint-Barthélemy.

\section{References}

1. Caserio-Schönemann C, Bousquet V, Fouillet A, Henry V. 2014. Le système de surveillance syndromique SurSaUD ®. Bull Epidemiol Hebd (Paris). 3-4, 38-44. 